\title{
THE NUTRITIONAL HABITS OF FEMALE STUDENTS AGED 18 TO 25
}

\author{
A. Andonova* \\ Department of Health Care, Faculty of Medicine, Trakia University, Stara Zagora, Bulgaria
}

\begin{abstract}
The main factors for establishing nutritional culture are the national traditions, family taste preferences and finances. After graduating from high school, some girls continue their education. Often, they have to break away from the home environment and change completely or partially their lifestyle and nutritional regime.

The purpose of the research is to establish the nutritional habits of the female students aged 18 to 25 who do not live with their family.

Materials and Methods: For the purpose of the survey, an inquiry card was made. An anonymous survey was conducted with 70 female students aged 18-25 who do not live with their families. The survey data were processed with mathematical and graphical methods - Microsoft Office Excel 2003.ink.

Results: The study found out a negative trend: $60 \%$ of the female students eat twice a day, consuming mainly confectionery and carbonated beverages between both of the meals.

A major source of information about healthy nutrition for students is Internet, but most of the young women get the necessary information from school/university. The highest number of students indicates that they partially respect the principles of healthy nutrition. The female students identify as the most harmful food sugar products and fried food, fruit and vegetables as the most useful types of food. Most of the students eat at home, as most often they buy takeaway.

Conclusions: The study found out that students are aware of the basic principles of healthy nutrition, but relatively high number does not follow them. It is a positive fact that the main source of the necessary information besides Internet is school and / or university. Despite not following all the principles of healthy nutrition, most of the students have a proper nutritional pattern and have a critical attitude towards their own diet regime.
\end{abstract}

Key words: healthy eating, information, students, harmful food, healthy foods

\section{INTRODUCTION}

The formation of nutritional habits begins from the earliest childhood.

Childhood andadolescence are critical periods for health and development as the physiological need for nutrients increases and the consumption of a diet of high nutritional quality is particularly important. Eating habits, lifestyle and behavior patterns are established during this period that may persist throughout adulthood. Patterns of eating have a significant influence on health and well-being. (1)

The main factors for establishing nutritional culture are the national traditions, family taste

\footnotetext{
*Correspondence to: Albena Andonova, Faculty of Medicine, Department of Health Care, Trakia University, Bulgaria, Stara Zagora, Str. Armeiska 11,e-mail: albena.andonova@trakia-uni.bg
}

preferences and finances. In teenage years, especially in girls, with the physiological changes in the body (secondary sexual characteristics, weight, growth, skin, hair, etc.), under the influence of the fashion trends for the beautiful woman's vision, the modern tendencies for healthy eating and freedom to choose food during the day, a change in the nutritional habits starts to be observed. When this period ends, in some girls the changes in these habits are positive and in other ones are negative. After graduating from high school, some girls continue their education. Often, they have to break away from the home environment and change completely or partially their lifestyle and nutritional regime. Proper nutrition at young age is one of the factors forming the quality of life of adults and elderly people. 
The problems of nutrition in an age aspect are of interest to mankind from ancient times. This issue is especially relevant in the context of good health and active longevity. (2)

In recent years, the eating habits of young people have deteriorated, although for many of them, healthy lifestyle, proper nutrition and sport are becoming valuable.

There are many risk factors that will, in long term, negatively affect the health of young people. Such ones are: smoking, alcohol use, psychotropic substances, sexual behavior, reproductive problems, HIV/AIDS, reduced physical activity and, last but not least, unhealthy nutrition.

In the context of the above and a number of national and European studies and policies, an updated National Youth Strategy (2014-2020) has been developed and adopted, setting out the main frameworks and defining the vision, goals and priorities for development of young people in the country. Special attention is paid to unhealthy nutrition among young people.

State policy, related to youth is based on the priorities set out in the National Programming and Strategy Documents, as well as on the principles and guidelines in the acts adopted by the institutions and bodies of the European Union.

Students have specific energy needs. During the sessions, the daily energy value of the accepted food for men should be $2350 \mathrm{kcal} /$ day on average and $1850 \mathrm{kcal} /$ day for women. A five-time diet regime with increased intake of amino acids, vitamins, mineral salts, lycithins, choline, etc. is recommended. (3)

Having a healthy nutritional regime in mental workload and relatively sedentary lifestyle in students has a positive impact on the academic achievements. Contented and balanced nutrition reduces stress level and the risk of health deterioration, and also helps to tackle the psycho-emotional stress during training and exam sessions.

Student health, nutrition, and quality of life is a problem in which research is being conducted to study the awareness of healthy nutrition for young people, (4-7) to establish culture of nutrition and quality of life. Surveyors analyze the results and offer grounded solutions to overcome negative trends and identify specific national characteristics in nutrition and quality of life of students. (8-16)
Special attention should be paid to the young women, who in the future will have to develop their own health and labor potential, to generate and nurture the future generation, by the society and research scientists.

\section{PURPOSE}

The purpose of the research is to establish the nutritional habits of the female students aged 18 to 25 who do not live with their family.

\section{METHODS}

For the purpose of the survey, an inquiry card was made. An anonymous survey was conducted with 70 female students aged 18-25 who do not live with their families. The survey data were processed with mathematical and graphical methods - Microsoft Office Excel 2003.ink.

Tasks - to find out the usual diet regime, preferred foods, presence or lack of critical attitude to your own diet regime.

\section{RESULTS}

In the modern world, getting information about healthy lifestyle is an easy and quick process due to the information technologies and the implementation of scientific achievements in a number of sciences - medicine, biochemistry, chemistry, etc. The main source of information about healthy nutrition for students is Internet $(82.94 \%)$. The impact of social network publications is also rising steadily, but the extent to which the information spread there is true, is difficult to find out. It is important to note that $70.07 \%$ of the survey participants get information from credible sources - school and / or university.

Healthy lifestyle is becoming more and more popular among educated young people. In recent years, there have been various information campaigns promoting healthy eating. Nutritionists and dieticians provide information about the energy content of food products, their proper combining and processing before consumption. That is why almost all respondents report that they know the principles of healthy nutrition. Most of the students think they partially respect the principles of healthy eating (74.36\%) and only $7.15 \%$ do not follow them.

Traditionally, we eat three times a day, with two intermediate meals allowed. Students have a busy daily schedule, characterized with mental tension. The proper daily distribution of the food amount is an important factor for their physical and mental comfort. The study found out a negative trend in the daily nutrition $60 \%$ of the female students eat twice a day. 
Very often, between the two meals young women have mainly sugar desserts and carbonated beverages. An alarming fact is also the daily consumption of confectionery $(45.76 \%)$.

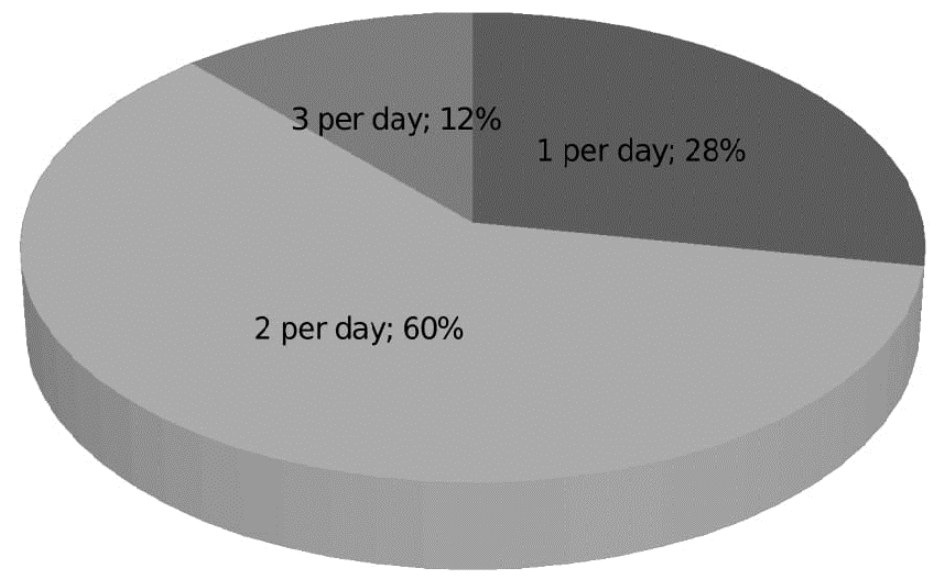

Figure 1. Number of meals during the day

Various and complete nutrition includes intake of different groups of foods. The study found out which types of food, how many times a day, and a week, and in what form are consumed by the young women.

Vegetables and fruit are a major source of vitamins, minerals, fiber, sugar, etc. Their inclusion in the diet regime helps maintain and improve health and normal body weight. Almost all respondents indicate that fruit and vegetables are the most useful types of food, with $62 \%$ consuming fruit daily and vegetables $-63 \%$. There are not vegetarians in the group of the respondents.

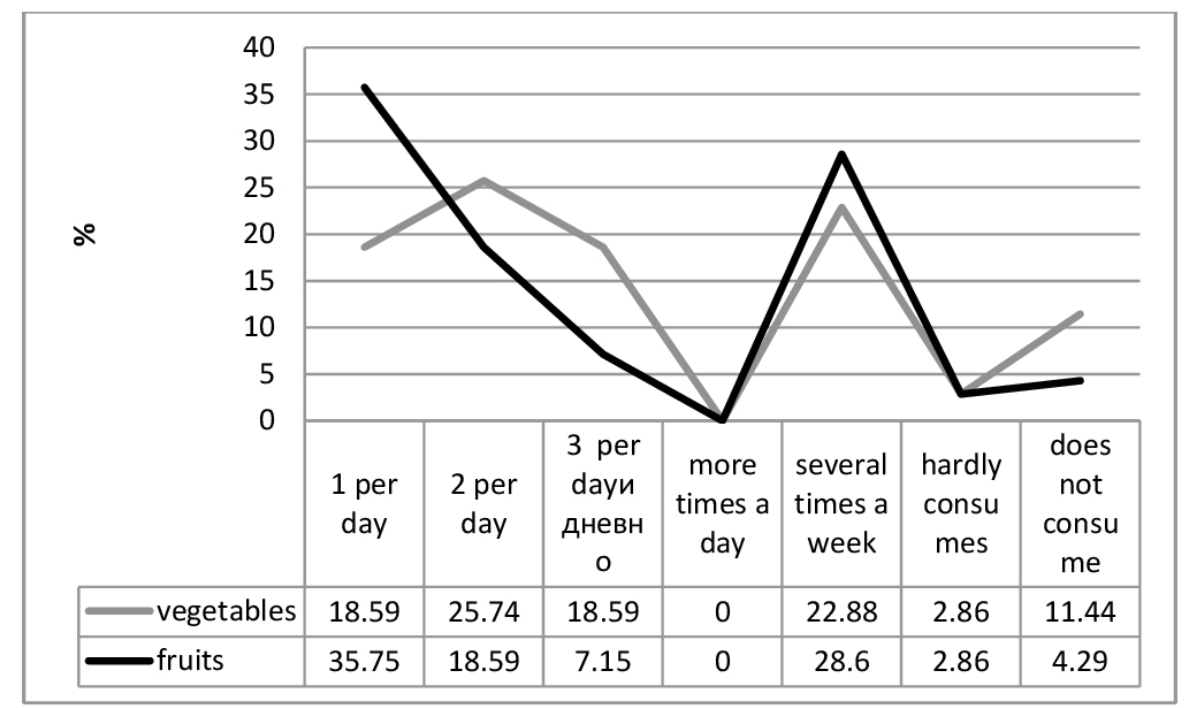

Figure 2. Consumption of fruits and vegetables during the day

With the increase in the number of people, keeping healthy diet regime, technologies that support quality food processing have developed. More and more popular among young people is the consumption of fresh and smoothie. About $35 \%$ of the respondents have fruit and vegetables in smoothie every day. Such a number drink several times a week fruit and vegetables, processed in this way. The rest of the women surveyed indicated that they would consume fruit and vegetables in this form if they had the necessary equipment for their preparation. This tendency can be ambiguous. Fresh and smoothie are easy way to eat fruit and vegetables, but the oral health requires chewing food to keep your gums, teeth, facial muscles and other parts of your digestive system healthy.

Milk and dairy products are a major source of protein, calcium and other valuable ingredients. Almost half of the respondents consume daily milk $44 \%$ and dairy products $59 \%$. 


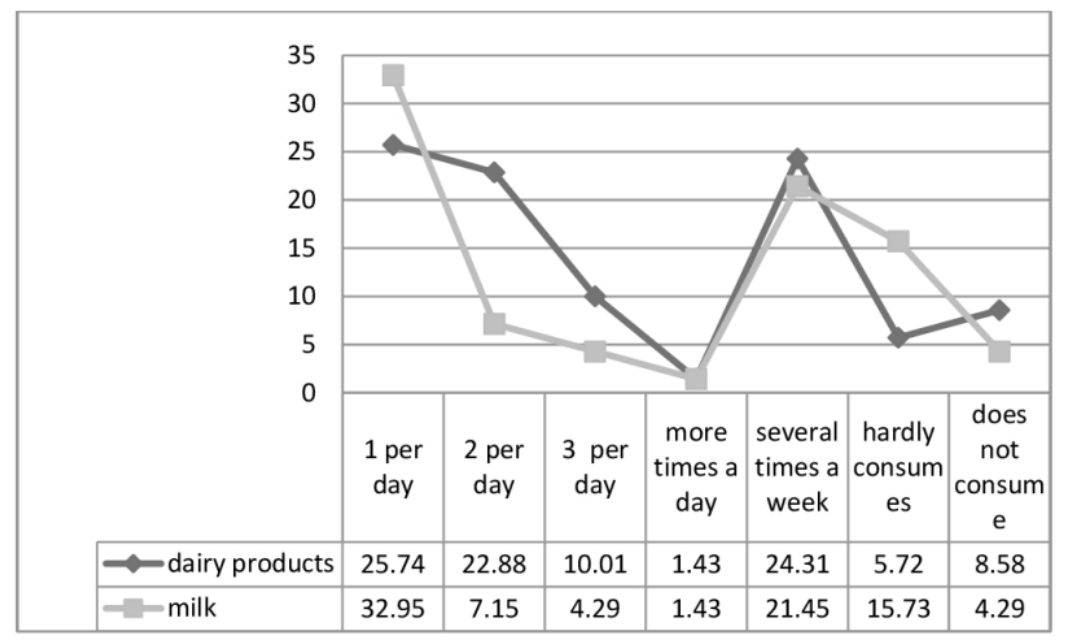

Figure 3. Consumption of milk and dairy products

The study found out that $44 \%$ of young women consume meat several times a week and about $30 \%$ - every day. Nowadays the harmful effects of the preservatives are increasingly spoken. The mass media have begun publishing information that the sausages have high content of them. This reason is indicated as the main motive for their decision not to consume or almost not to consume sausages by nearly half of the respondents.

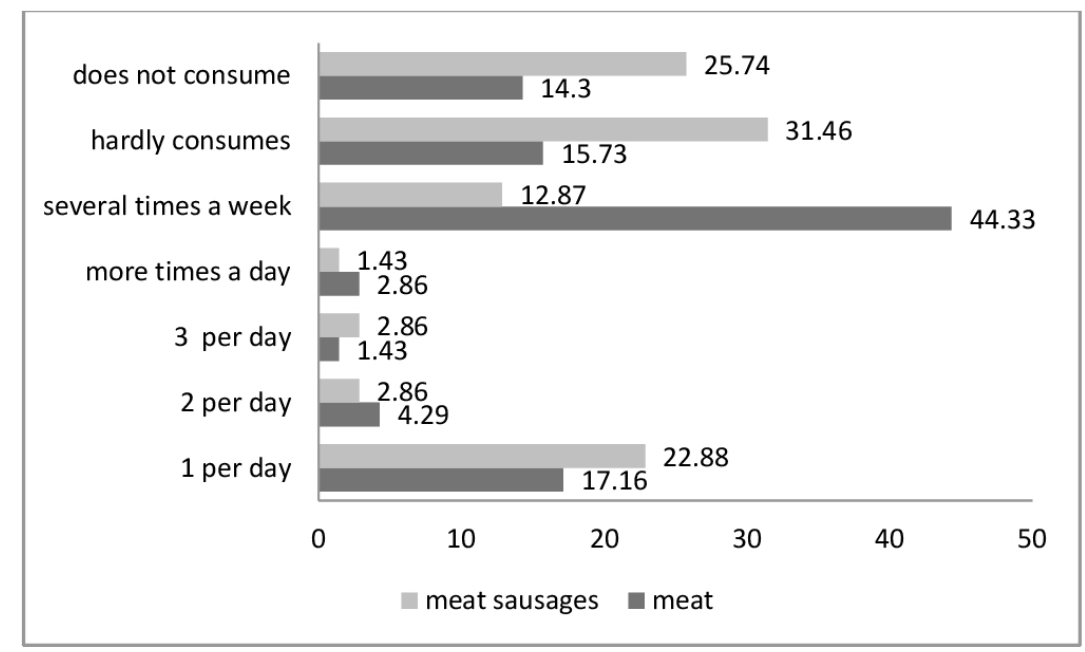

Figure 4. Consumption of meat and meat sausages

In the Bulgarian food culture, bread takes an honorable place. Traditionally, elderly people consume bread at every meal. An interesting fact is that the data from the study found out a tendency to reduce the intake of bread by the young women. Almost $40 \%$ of the respondents rarely eat or do not include bread at all. Breadconsumers say they prefer the whole-grain bread, as healthier. Consumption of wholegrain bread may be associated with the pursuit to healthy lifestyle by women. (17) Bakery products show almost equal groups of consuming and almost non-consuming people this type of food (about 50\%).

Knowing the useful types of food is important for healthy nutrition, as well as knowing the harmful ones. The way of cooking is also important. The female students identify sugary products $(58.63 \%)$ and fried food $(42.9 \%)$ as the most harmful types of food.

Most students eat at home (82\%), and only few of them prepare their meals themselves, most of them have takeaway (58.63\%). The female students living in dormitories very often do not have appropriate conditions to prepare their own food or cannot or do not have time and desire for that. Most often they buy food from fast-food or from the so-called. "Hot showcaase" from the supermarket.

Prepared food of this type is also preferred because of low price, provided sitting place, in spite of the lower food quality. (18) 


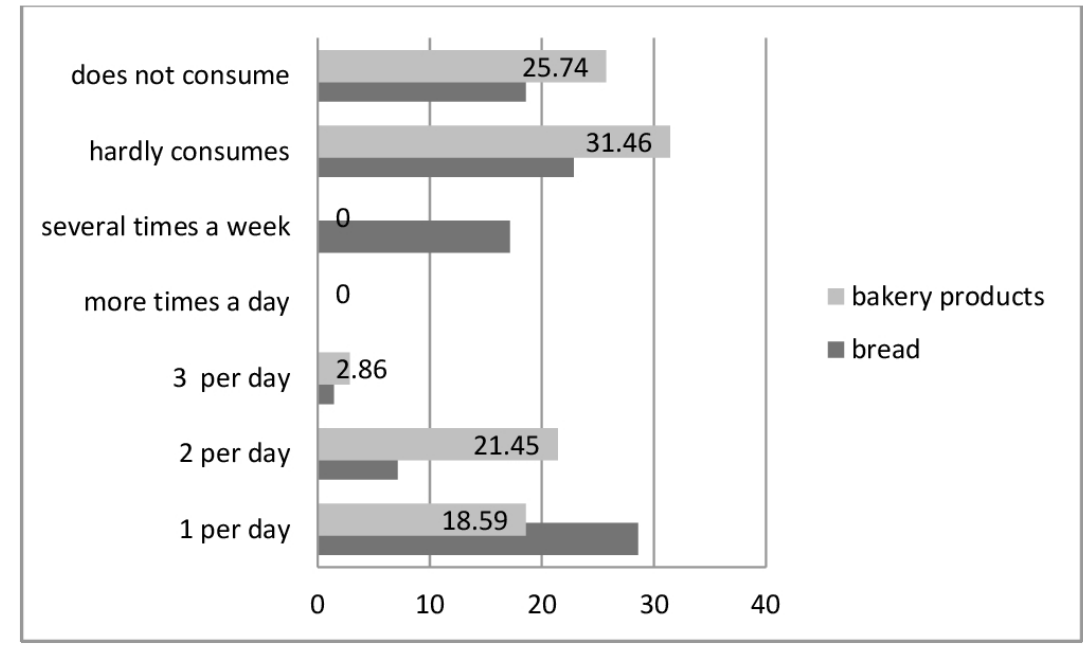

Figure 5. Consumption of bread and bakery products

\section{RESULTS}

The study found out a negative trend: $60 \%$ of the female students eat twice a day, consuming mainly confectionery and carbonated beverages between both of the meals, and $45.76 \%$ consume sweets every day.

A major source of information about healthy nutrition for students is Internet (82.94\%), but most of the young women get the necessary information from school / university $(70.07 \%)$. The highest number of students indicates that they partially respect the principles of healthy nutrition $(74,36 \%)$ and only $7,15 \%$ do not respect them.

$44 \%$ of the young women surveyed consume $44 \%$ milk a day, and $23 \%$ - meat. About half of the respondents hardly ever consume or do not eat sausages at all.

It was found out that almost $40 \%$ of the female students consume or not consume bread at all. Almost equal groups of consuming and nonconsuming bakery products were indicated.

About $35 \%$ of the respondents take daily fruit and vegetables in the form of fresh / smoothie, and such percentage take the same several times a week. The same percentage of students says that they do not have the necessary equipment for their preparation and therefore do not consume.

The female students identify as the most harmful food (about 60\%) - sugar products and fried food.

The respondents assess fruit and vegetables as the most useful types of food, and about $60 \%$ consume them daily.

Most of the students eat at home (82\%), as most often they buy takeaway.

\section{CONCLUSIONS}

The study found out that students are aware of the basic principles of healthy nutrition, but relatively high number does not follow them. It is a positive fact that the main source of the necessary information besides Internet is school and / or university. Despite not following all the principles of healthy nutrition, most of the students have a proper nutritional pattern and have a critical attitude towards their own diet regime.

The development and practical implementation of international and national strategies and programs for healthy lifestyle, including healthy nutrition, is a very important process for protecting and strengthening personal and public health especially in children and young people. The emphasis should be on young people, in particular women, who will need to develop their own health and work potential in future, to have and bring up the future generation. Creating rational eating habits and healthy lifestyle should start from the early childhood and should continue throughout life.

\section{REFERENCES}

1. Saurina, N., Purwaningrum, S. W., \& Adisusilo, A. K., Bikers Game-Simulation Game to Introduce Calories for Children in Aged 7-8 Years Old. International Journal of Emerging Trends \& Technology in Computer Science, 5. 6: 67-74, 2016

2. Milcheva, Hr., M. Dimova, A. Andonova, Nutrition problems in adults, International congres proceeding. 1Oth Internationat gerontotogical congress, Belgrade, Serbia, pp. 74-79, 2018.

3. Terzieva, V, Kolev I, Mihailov K, Peev P, Angelova M, Vitkov B, et al., Collection of recipes for student chairs - student and 
teaching nutrition; "Interprint", Sofia, Bulgaria, 1991.

4. Kim, Jung-Min, and Guen-Hee Han., The effects of mass media, tendency for appearance comparison and BMI on female high school and college students' eating behavior. Journal of Korean Home Management Association 26.4: 73-83, 2008

5. Freire SC, Raats MM and Fisberg M., The Influence of Specialists and Media on the Practice of Physical Activity, Body Image and Eating Behavior among Brazilian Students. Ann Nutr Disord \& Ther. 5(1): 1051, 2018

6. Aida, Halimic, et al., Effect of price and information on the food choices of women university students in Saudi Arabia: An experimental study. Appetite. 123: 175182,2018

7. Kyuchukova S., Nutrition and future nurses, XXX Scientific and Technological Session. KONTAKT 2012, ed. TEMOTO, pp. 190-192, 2012

8. Mansor, N., Zuraida, M., Abdullah, Z., \& Rashid, K. M, Meal Selection of Malaysian University's Students. The Social Sciences, 11(31), 7461-7466, 2016

9. Eman R. El- Refaay, Amel I. Ahmed, Nagwa M. Salem, Development of WebBased Nutritional Health Education Module. Journal of Nursing and Health Science. 6. 3. Ver. IV, pp 62-74, 2017 DOI: $10.9790 / 1959-0603046274$

10.Sadaf Ali, Greeshma B. Kotian, Dr. Nivedita L. Rao, Nutrition and Healthy Lifestyle: Knowledge, Attitude and Practice in Medical Students of Yenepoya Medical College, Mangalore. A Questionnaire Based Study. Int. J. Pharm. Sci. Rev. Res., 45(2); Article No. 18, pp 99-103, 2017
ANDONOVA A.

11.Breitenbach, Zita, et al., Examination of Hungarian college students' eating habits, physical activity and body composition. European Journal of Integrative Medicine. 8: 13-17, 2016

12.Reed, Julian A., et al., Using "point of decision" messages to intervene on college students' eating behaviors. American Journal of Health Promotion 25.5: 298300, 2011

13. Valladares, M., et al., Association between eating behavior and academic performance in University Students. Journal of the American College of Nutrition, 35.8: 699703, 2016

14.da Silva, W. R., Campos, J. A. D. B., \& Marôco, J., Impact of inherent aspects of body image, eating behavior and perceived health competence on quality of life of university students. PloS one, 13.6: e0199480, 2018

15. Amiraian, D., and J. Sobal, Dating and eating. How university students select eating settings. Appetite, 52.1: 226-229, 2009

16.Bradanova V, Stoynovska M, Stavev N, Boyanov L, Petkov K. Current problems of the organized student nutrition at the Medical University - Pleven. Science \& Technologies. Medicine II (1) , 2012

17. Bakken, Toril, et al. Characterization of Norwegian women eating wholegrain bread. Public health nutrition, 18.15: 28362845, 2015

18.Balińska, A., Konkurencyjność obiektów typu fast food w ocenie studentów sggw, Research Papers of the Wroclaw University of Economics / Prace Naukowe Uniwersytetu Ekonomicznego we Wroclawiu . Issue 475, pp 23-32. 2017

DOI: $10.15611 /$ pn.2017.475.02 